\title{
TEACHING LEXICALLY FROM VERTICAL LISTS TO HORIZONTAL ALTERNATIVES
}

\author{
by \\ Dedy Subandowo \\ Muhammadiyah University of Metro, \\ Lampung Indonesia \\ dedy.subandowo@pbiummetro.ac.id
}

\begin{abstract}
Teaching vocabulary for young learners by giving it into semantic set will not help them understand how the words are used. In elementary coursebook, the vocabulary is presented in list semantic set that is semantically related items such as jobs doctor, teacher, lawyer etc. or colours: red, blue, yellow etc.). This idea is really restrictive to develop the students' vocabulary mastery. It seems that teaching vocabulary in semantically related items is counter-productive but this idea has never been taken on board. The question is Why do students have to go through so much learning of things which they are hardly ever likely to say?. (Estatiev, 2015) and (Leoselivan, 2014) introduce the way to teach students' vocabulary by developing the students' idea through communicative purpose beyond the basic description. Developing alternatives in horizontal lists instead of semantic set lists will make learners find the words in which they are likely to go with (co-text) rather than with other words sharing the same superordinate concept. The easy samples are colour and animal. Focusing them in three at a time and present would be more affective to fix the word collocation such as noun that can go along with adjective or noun collocation.
\end{abstract}

\section{Keyword: EFL, Semantic Set, Teaching Lexically, Vocabulary Mastery}

\section{Introduction}

Teaching new vocabulary in semantic sets such giving the example of vehicles: car, train, bus, truck, motorcycle, or color: red, blue, black, white, purple and etc will not give any significant process in acquisition of language learning. (Walkley, 2015) offered on 'Lexical Sets and Topic Vocabulary' on the BELTA blog and offered the 
way to teach in the class. The students would learn 10 random words faster than 10 words from a set. This idea has been proven by research, but it does not indicate a course book design (Leoselivan, 2014). Since 1990 teaching semantically related items is counter-productive. It can be seen from the elementary coursebook that presented in lists of semantically related items. Furthermore, Leoselivan takes point of view that the course books and teachers are set by the grammatical syllabus that highlights present simple in order to step ahead on present continuous, past simple, and so on. Yet, as a teacher, the grammatical syllabus of the standard course book is a guidance that must be followed. (Marekkiczkowiak, 2015) said that the course book, and by extension the teacher, prescribes what the student must learn today, often stopping them from going a step beyond that. It would be good, if teaching lexis starts with simple phrase. This statement is in line with Marekkiczkowiak that started to :

Teach phrases containing more 'advanced' grammar easily to beginners especially where we make use of translation - which could allow for a wider variety of language earlier on. Yet we become primed to expect certain grammar and words at certain levels which prevents us from seeing how we can help students say more of what they want to say, sooner. (Marekkiczkowiak, 2015)

The big question in language teaching is why the students must learn many things that they do not really know or say. How they describe people is not an everyday thing than describing room. The simple expressions to start are "I am student", "he has white skin". Or "There's an empty chair across the street and there are some bananas and an apple". This is because there will tend to be a wider communicative purpose beyond the basic description.

Why do you take a short course in this semester? It will spend three months.

This class room is really small. There are only some chairs in it. The condition of the class is really bad. It must be cleaned so that's why the students feel comfortable. It has happened since the beginning of this year. One thing for sure, even this class has limited number in receiving the students, it will be our pride. 
The above examples elaborate that the first sentence is easier than the second sentence which is built by complex sentence. The rule guides the teacher when teaching grammar. It requires practicing the verb to be before present simple tenses, before is/are or modal.

This idea will make the students difficult to practice in real life. The students must wait so long to build and combine the right words. They only focus how the words fit the pattern, especially in applying noun and adjective that sometimes confuses them. If the students practice these ways, there would be some problems occur. Firstly, it will encourage them to learn lexical set. Second, the students devote time in learning less frequent words. Third, the students will make a slot-filling mentality that how to fit $\mathrm{X}$, they can fill any kind of nouns or adjectives.

\section{Theoretical Review}

\section{Semantics Set and Interference}

Based on the research done by (Tinkham, 1997) shows that there are two main conditions that affect learning new word. One group will receive a list of words that have relative semantic set, while the others are given random, semantically unrelated words. The fact revealed that list-learning of unrelated words yielded better results as the second group performed significantly better when they were asked to recalled the target words. Another researcher after Tinkam, (Waring, 1997) repeated the same experiment project with two groups of English Japanese Learners. After years later, (Erten \& Tekin, 2008) did the study of 60 Turkish 4th graders, and exposed the same negative affect on recall and learning when new words were combined in the same semantic set.

The study results are usually construed with the interference theory. This lights the similarity between the items learned at the same time hinders learning and retention. In vocabulary teaching, it can be described that the words have close relation when the words learned at the same time, they will interfere each other or the words will 
have same characteristics. It can be seen by the students who learned the vocabulary they remember. This phenomenon divulges the students how to spell and pronounce the words and finds the meaning but they will get confused which word goes with each meaning.

There is a reason why learning semantic list gives counter-productive. Providing vocabulary in related by virtue of their belonging to the same superordinate category such as; car, bus, plane, motorcycle, truck for TRANSPORTATION would not give students much information about how the words should be used. The same is true that paradigmatic relationship also facilitates counter-productive such as synonyms and antonyms (Neville, 1989). Paradigmatic relationship is given by Saussure that related two atoms that must be long to same level. Paradigmatic relations range from semantic fields to well defined logical relation such as hyponymy, co-hyponymy, hyperonymy, synonymy and antonymy (Mehler \& Kohler, 2007).

\section{Semantic Vertical Lists}

Regardless the above ideas, a coursebook in elementary school listed vocabulary in semantic set. It is done because of the category primes (McNamara, 2005). The vocabulary is usually used to brainstorming is commonly presented with the following categories:

\begin{tabular}{|l|l|l|l|l|l|}
\hline Transportation & Colors & Clothes & Animal & Classroom Object & Food \\
\hline Bicycle & Red & Skirt & Cat & Desk & $\begin{array}{l}\text { Ice- } \\
\text { cream }\end{array}$ \\
\hline Car & blue & Shirt & Horse & Table & $\begin{array}{l}\text { Fried } \\
\text { chicken }\end{array}$ \\
\hline Truck & Pink & Scarf & Tiger & Chalk & Pizza \\
\hline Train & White & Trousers/pants & Lion & Eraser & Pasta \\
\hline Plane & Black & Hat & Butterfly & Whiteboard & Salty egg \\
\hline Taxi & Purple & Jacket & Elephant & pencil & Meatball \\
\hline bike & Brown & Blazer & dog & ruler & Noodles \\
\hline
\end{tabular}

Examples are taken from (Leoselivan, 2014) 


\section{Developing Horizontal Alternatives}

Teaching new vocabulary can be done by using horizontal alternatives instead of vertical list. The example is to teach how the words are likely to go with the co-text. Color would be an easy category to teach. Selvian classified the alternatives by taking the example from color, animal, classroom object, transportation, and food. These could be also changed with another class such as music, flower, flag, etc.

\section{Color}

Focusing on teaching with three at a time and present by the use of how noun can go along with other word class (such as adjective + noun or noun + noun) is more effective, instead of teaching a list of set vocabulary.

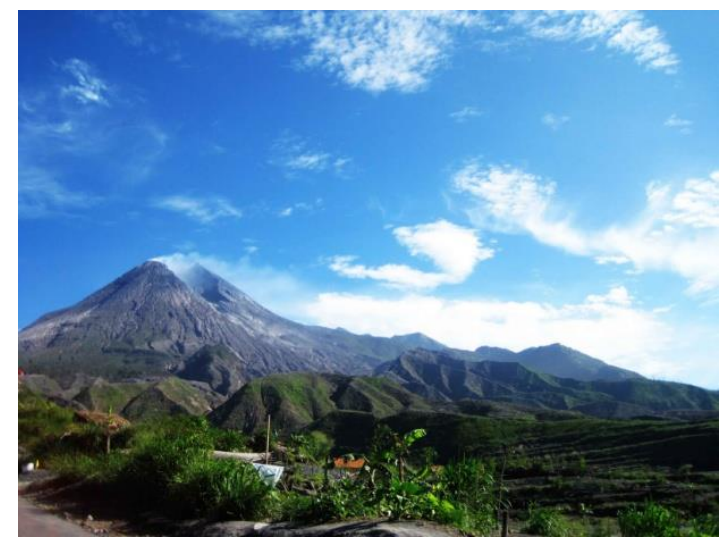

For example

Blue sky

White cloud/ dress

Green trees

Another example can be added by the three following lesson:

Black hole

Green Yard

Brown sand

The picture can be used to teach vocabulary for the country in which mountain is part of its landscape. It would not be relevant for the students whose country does not have mountain to describe. The mountain can be changed to land or sky, so blue sky was suggested instead. The phrase white cloud can be combined with blue sky (white clouds in the blue sky). The picture above can illustrate the learners to delineate with immediately useable language. Mnemonic is also a device to teach how alliterative patterns such as red dress and green grass which have been used to facilitate learning (Boers \& Lindstromberg, 2005). 


\section{Animal}

The combination between animal and color could be combined. Treat the students by introducing them with 3-4 animal with their

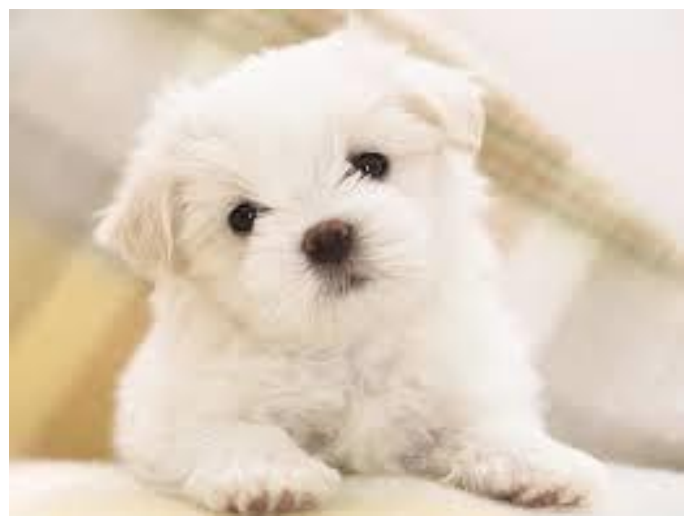
color in the same time. In the first meeting, short and easy combination would be easy to remember such as black cat, blue bird, white tiger. Add another different color and combination, pink cat, yellow dog, purple cow, green snake, brown bee, red rabbit.

The picture is taken from indotopinfo.com

\section{Classroom object}

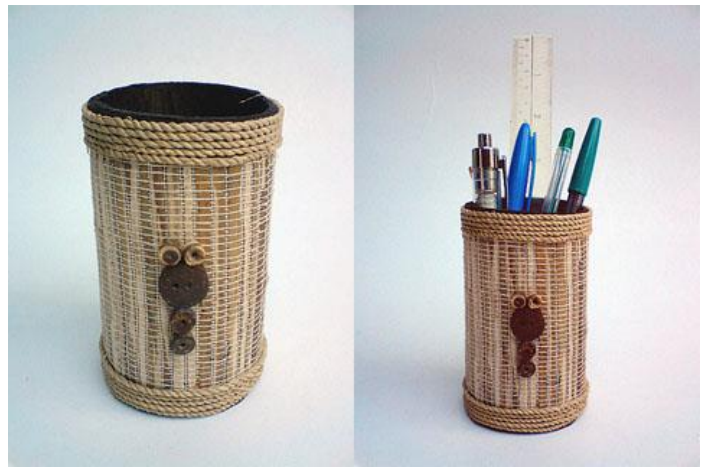

In the classroom object, one possible thing to do is ask the student to combine the real object around them in the class. The object can be written in list and put together with colours.

Example:

1. Green pencil case

2. Black pencil

3. Orange ruler

4. White pen

The other idea that can be used to develop the alternative is adding the grammar to the list.

1. Do you have pencil/eraser/history book?

2. Have you done drawing a pencil case?

3. Can I borrow your pen?

4. Would you lend me your pencil/book ? 
5. Which shoes/pants/bag do you want to buy?

\section{Transportation}

This alternative can be used to build a simple grammar combination and collocation. For the example, TPR can be added to create students' ideas in producing semantic set. This method can investigate some interesting relationship between language and movement (Syrja, 2011). For example: She always goes to school by cycle. We take the bus to school.

1) Another expression can be used to do the same thing, like:

2) Drive a truck/car/van

3) Ride a motorcycle/bike/scooter

4) Get on/off the train/bus/ subway.

5) I get out of a car/taxi.

6) How do you get to school/campus/work?

\section{Food}

This topic will give great fresh ideas for the students in classroom practices. The various vocabularies for food are another thing that students like to add to the list (Stone, 2002). The horizantal group effects the semantic list that the students likely most to eat. Teaching another food that is from different place is recommended by (Kryszewska, 2005).

Luwak coffee from Indonesia

Tea from Japan

Football from England

Orang utan from Borneo

Elephant from Thailand

Cars from India 


\section{Conclusion}

The issue of teaching based on coursebook syllabus is constrained by the syllabus and textbooks which present new vocabulary in semantic sets. The semantically related items can be developed horizontally by teaching three collocations at once rather than one at a time. This practical way hopefully help the teacher adapt the context to the class. The initial counter with new item is being the main concern on this research, whereas additional way can be used like consolidating vocabulary through semantic sets and drawing students' attention to recurring patterns, like -er suffix.

\section{Bibliography}

Boers, F., \& Lindstromberg, S. (2005). Finding ways to make phrase-learning feasible: The mnemonic effect of alliteration. System , 33(2), 225-238.

Erten, İ. H., \& Tekin, M. (2008). Effects on vocabulary acquisition of presenting new words in semantic sets versus semantically unrelated sets. System , 36(3), 407422.

Estatiev, V. V. (2015, Jan 31). Lexical Sets/Topic Vocabulary by Andrew Walkley. Retrieved April 3, 2015, from beltabelgium: http://www.beltabelgium.com/lexical-setstopic-vocabulary-by-andrew-walkley/

Kryszewska, P. D. (2005, March 03). Chunking for beginners ( Lexical Approach). Retrieved May 19, 2014, from Pilgrims: http://www.hltmag.co.uk/mar03/less.htm

Leoselivan. (2014, March 1). Leoxicon. Retrieved march 20, 2015, from Horizontal alternatives to vertical lists : http://leoxicon.blogspot.nl/2014/03/horizontalalternatives-to-vertical.html

Marekkiczkowiak. (2015, February 6). Teaching Lexically. Retrieved March 20, 2015, from Teflreflection: https://teflreflections.wordpress.com/2015/02/06/teaching-lexically/

McNamara, T. P. (2005). Semantic Priming: Perspectives from Memory and Word Recognition. New York: Psychology Press. 
Mehler, A., \& Kohler, R. (2007). Aspects of Automatic Text Analysis. New York: Springer.

Neville, R. C. (1989). Recovery of the Measure: Interpretation and Nature. New York: State University of New York Press.

Stone, R. (2002). Best Classroom Practices: What Award-Winning Elementary Teachers Do. London: Corwin Press Inc.

Syrja, R. C. (2011). How to Reach and Teach English Language Learners: Practical Strategies to Ensure Success. San Fransisco: Jossey-Bass Teacher.

Tinkham, T. (1997). The effects of semantic and thematic clustering on the learning of second language vocabulary. Second Language Research, System, 21(3), $371-380$.

Walkley, A. (2015, January 15). beltabelgium. Retrieved march 20, 2015, from Lexical Sets/Topic Vocabulary by Andrew Walkley: http://www.beltabelgium.com/lexical-setstopic-vocabulary-by-andrew-walkley/

Waring, R. (1997). The negative effects of learning words in semantic sets: A replication. . An International Journal of Educational Technology and Applied Linguistics , System, 25(2), 261-274. 